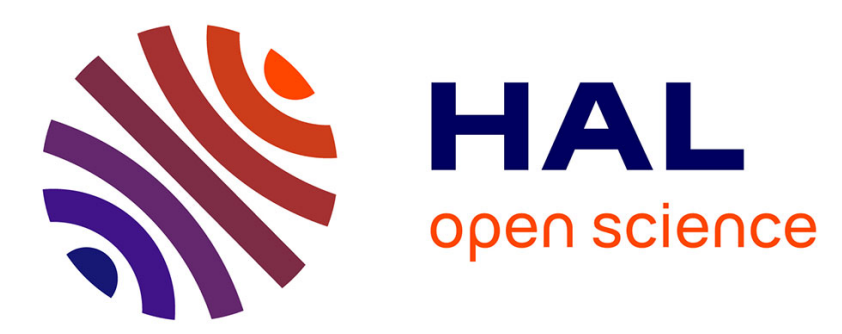

\title{
Logistics Performance of Actors in the Wine Supply Chain
}

\author{
Jerôme Chandes, Dominique Estampe
}

\section{To cite this version:}

Jerôme Chandes, Dominique Estampe. Logistics Performance of Actors in the Wine Supply Chain. Supply Chain Forum: An International Journal, 2003, 4 (1), pp.12-27. hal-00767174

\section{HAL Id: hal-00767174 \\ https://hal.science/hal-00767174}

Submitted on 19 Dec 2012

HAL is a multi-disciplinary open access archive for the deposit and dissemination of scientific research documents, whether they are published or not. The documents may come from teaching and research institutions in France or abroad, or from public or private research centers.
L'archive ouverte pluridisciplinaire HAL, est destinée au dépôt et à la diffusion de documents scientifiques de niveau recherche, publiés ou non, émanant des établissements d'enseignement et de recherche français ou étrangers, des laboratoires publics ou privés. 


\section{Logistics Performance of Actors in the Wine Supply Chain}

The study was coordinated and supervised by

Jérôme Chandes,

Head of Logistics at Euralog, and

Dominique Estampe, Dean of ISLI.

Surveys, data analyses and findings were carried out by 4 ISLI students :

Romain Berthomier,

Laure-Anne Courrié, Lingli Han and Sylvain Marquevielle

In an environment marked by ever-greater international competition, wine sector companies have been seriously questioning the structure of their entire logistics chain. This is due to the emergence of new actors (i.e., large retailers); the diversification of service providers' product offers; and the different rapprochements between actors in this branch. These are all signals that have caused companies to question their logistics strategies. The present study aims to raise wine supply chain actors' awareness of the importance of adopting a logistics approach, by enabling them to assess their performance in this field and to compare it with the chain's other actors and with top-performing companies across the world.

Following on from studies it made of the automobile and electronics sectors, ISLI carried out a WCL model-based analysis of the wine sector. This 2003 study has been mainly geared towards actors in the Bordeaux region. In the future it will cover other wine-growing districts in France and abroad.

The study relies on the WCL (World Class Logistics) model that Michigan State University developed. This model uses 68 questions to evaluate companies' Supply Chain Management performances. The questionnaire was filled out by several Logistics, Sales, Production and Purchasing managers in each interviewee company. The answers were analysed immediately, in the respondents' presence. This type of analysis tries to ascertain both the degree of integration between a branch's actors as well as the extent to which each masters the concepts driving their particular supply chain. Findings are then amalgamated amongst the various companies comprising the sectorial analysis.

The WCL model was chosen for several reasons:

- It enables analysis of the various types of companies (agricultural, industrial, commercial, service provider) to be found in the wine chain.
- It highlights relevant findings without requiring any further (unwieldy) auditing mechanisms, thus inducing a maximum of companies to take part in the survey.

- It encompasses all facets of Supply Chain Management, and does this by creating combined categories that are marked by the homogeneous nature of their constituents' performances.

The study shows that the wine sector has not yet become aware of how very important Supply Chain Management is to a branch's overall performance. This observation applies notably at the winemaker level, this being the link that centralises the greatest number of value-added operations. Winemakers have not yet started to adopt a supply chain integration and unification approach and are therefore achieving lower logistics scores than the other actors.

Service providers, whose business has been expanding rapidly, possess a much greater level of logistics maturity. They have therefore become the drivers of a more integrated supply chain meaning that they have been pushing their clients to implement best practices. 
Amongst the wine merchants interviewed here, some have already implemented high performance logistics policies and been very successful in this respect. Others have become aware of the usefulness of logistics thinking but in general will only act when an emergency comes up. The rise of branded wines being produced in an integrated supply chain that is piloted from the downstream side guarantees future growth for those wine merchants who have opted for this strategy.

The major retailers constitute the link in the wine chain that has attained the greatest logistics maturity. They are the main force pushing for better practices in this chain. The retail sector integrates all of its partners into its logistical operations. Numerous timed systems have already been set up, and internal and external performance measurement mechanisms help major retailers to evaluate their partners as a whole.

\section{The Wine Market}

\section{The world wine market}

The wine sector is a dynamic and ubiquitous member of today's world economy. $1 \%$ of the working population lives from wine, and wine production accounts for $1 \%$ of all farmland.

Europe currently accounts for about two-thirds of the world's vineyards and three-quarters of its wine output. European Union wine production has fallen by some 7 millions hectolitres from its 2001 levels however, notably due to smaller output from Italy and France. New World vineyards have been experiencing strong growth on the other hand. In 1990 these regions only accounted for $8 \%$ of world's wine-growing area. By 2000 this had doubled to $15.8 \%$. Over the past 6 years Australian vineyards have grown by $108 \%$ in area. For New Zealand and Chile the figures are $100 \%$ and $95 \%$, respectively.

In terms of consumption, trends are down in Europe and up in the New World countries.

Wine consumption in Europe has been dropping for several decades now in this region's main wine-growing countries. This fall has been accompanied by higher quality.

On the other hand, consumption in Australia and New Zealand has risen by $10 \%$ over the past 5 years. New consumer countries have also been emerging, notably in Asia, where wine has started to become an alternative to other more traditional beverages.

\section{The French wine market}

Along with Italy, France is the world's leading producer of wine (with a 2000 output of 60 million hl). France's vineyard is the world's second largest in area, equal to Italy and right behind Spain. France is the world's leading wine exporter in value terms and second in volume after Italy. Its main clients are Europe, followed by the United

\section{Breakdown of World Wine production in 2000}

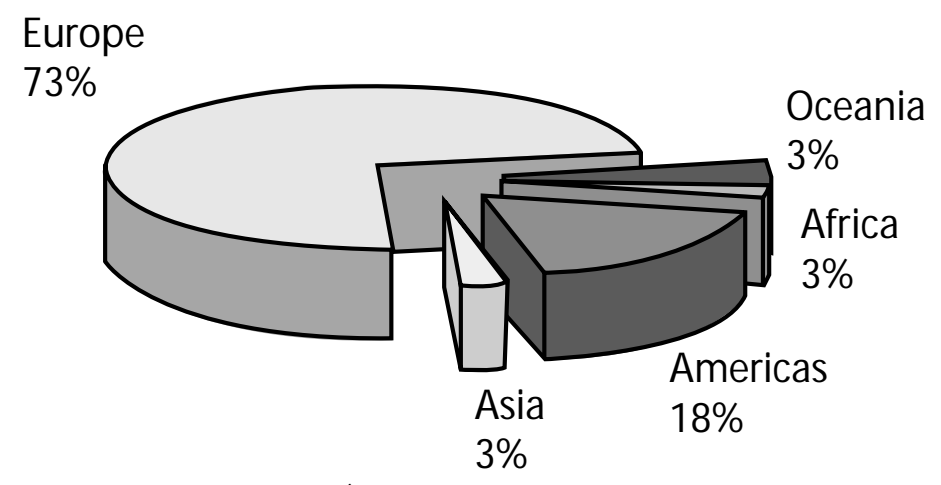

(Source : Office International du Vin)

States and Asia. The South-Central Languedoc-Roussillon region accounts for one-third of France's vineyard, vs. $17 \%$ for the South-West Aquitaine region.

4 categories of wines can be distinguished: AOC (Appellations d'Origine Contrôlées, Certified Origin Labels), VDQS (Vins Délimités de Qualité Supérieure, Designated Higher Quality Wines), Vins de Pays (Local Wines) and Vins de Table (Table Wines)

With 32.5 million hl France is the world's leading consumer market. Since the early 1960s French wine consumption has been cut in half, falling from 135 litres to 68 litres annually. Between 2000 and 2001 household purchasing volumes began to rise again but as the market has long reached its maturity stage growth rates have remained moderate. As a trend consumers are drinking less wine, but better quality. Purchasing of quality wines has risen, and there has been a concomitant drop in standard wines.

\section{The Bordeaux regional wine market}

Bordeaux is France's third largest wine-producing region with $17 \%$ of total output. The vineyard here stretches out over 150,000 hectares, $90 \%$ of which is classified as AOC. Bordeaux's wine sector includes 12,000 AOC businesses, 78 wine co-ops and winemaker unions and 400 trading houses. It provides 20,000 persons with full-time employment.

\section{Constraints and strategies of each actor in the wine chain}

\section{Winemakers}

Planting vines, making wine and getting bottles of wines to market are all strictly regulated activities. French law establishes mandatory production criteria. The vast majority of Bordeaux regional wines are classified $A O C$ and subject to the extremely strict production conditions set by the INAO (Institut National des 


\section{THE WO RLD CLASS LO GISTICS MO DEL}

The WCL model revolves around 4 areas of competency, themselves divided into various capabilities.

\section{Positioning}

Choice of strategic and structural orientations to optimise logistical operations

Strategy: implementation of financial and commercial objectives and of facility location decisions, plus the means to attain them

Supply Chain: synchronisation of resources via partnerships all along the logistics chain

Network: organisation and retail of physical resources

Human organisation: organising people and getting them involved

\section{Integration}

Means implemented to synchronise the whole of the logistics chain

Supply Chain Unification: ability to develop cooperative relationships with companies all throughout the logistics chain

Information Technology: investment in materials, software and networks and the adaptation there of to facilitate information processes and exchanges throughout the chain

Information Sharing: desire to exchange crucial technical, financial, operational and strategic data

Source: Michigan State University
Connectivity: a company's ability to exchange information in a format that is appropriate, responsive and readily usable in the logistics chain

Standardisation: implementation of joint policies and procedures to facilitate and improve logistical operations

Simplification: re-engineering of procedures to improve their efficiency

Discipline (getting people on board) : general acceptance of operational policies and procedures

\section{Agility}

Ability to maintain a balance between company performance and customer needs

Relevancy: ability to remain attentive to customers' changing needs

Adaptability: shortening of time needed to respond to exceptional customer demands

Flexibility: ability to adapt to unexpected circumstances

\section{Perfomance Measurement}

Evaluating logistics chain performance

Functional Assessment: management of assets, costs, customer service, productivity and quality

Process Assessment: setting up indicators all along the logistics chain

Benchmarking: comparison of performance measurements and processes with best practices
Appellations d'Origine). Moreover, specifications contained in winemakers' contracts with wine merchants or major retailers can be even more stringent than government ordinances.

New World wines are attracting more and more consumers and connectivity for an ever-greater proportion of the world market. The success of these competitors seems to stem from their ability to pilot production from the downstream side thanks to their integrated and highly concentrated structures. The challenge for French winemakers who want to meet this competition head-on is to find a balanced solution between their traditional methods and the new practices that the New World countries have been implementing.

Lastly, certain winemakers have pooled their complementary capabilities and created associations that will help them both to provide a better response to the various specifications being required of them and also to centralise a greater share of the overall value-added created in this branch - the purpose being to produce superior quality wines and to optimise sales prices.

\section{Wine merchants}

French wine sector actors have started to counter this offensive from New World wines by taking a closer look at what the market really wants. Wine merchants are closer to customers than winemakers are and will find it easier to ascertain consumers' real wishes. Yet they are currently in somewhat of a bind, being squeezed on the one hand by the major retailers and on the other by the fact that they lack the financial resources to efficiently manage their customer relationships.

One product-based solution could be to create branded wines. Hence the recent appearance of "French grape variety wines", which applies a similar logic. With branded wines it is easier to segment the market, thus to capture both potential consumers as well as newcomers to this product.

Regarding the creation of branded wines, if consistent quality is to be achieved contractual relationships will have to be set up both upstream and downstream. Specifications expressing winemakers' obligations in production and vinification terms will have to be implemented.

Branded wines are highly marketed products requiring considerable investments in marketing. With a profit rate of less than $2 \%$ of turn over, wine merchants are not in a position to market their wines all across the world. They lack the financial wherewithal to do battle with the new competitors.

Wine merchants are increasingly finding themselves in competition with other retail channels. Major retailers have become the predominant downstream actors in the logistics wine chain. Their 
influence in this branch has risen sharply over the past few years.

This balance of power is all the more significant since it plays out at two separate levels:

- The major retailers buy large volumes $(70 \%$ of the total market) and push prices downwards. They are serious competitors for wine merchants, especially since they have begun sourcing directly from winemakers;

- The major retailers are in a very strong bargaining position and constantly force wine merchants to compete with one another. This has caused wine merchants' profit margins to plummet, even as their quality constraints have become increasingly stringent.

Wine merchants have reacted to the rise of New World wines, and not just by working to improve the competitiveness of Bordeaux wines. Following a multi-pronged strategy, they have also been trying to take advantage of people's newfound interest in non-French wines. Towards this end they have been pursuing partnership strategies with foreign winemakers, or vertical integration strategies involving an acquisition of vineyards in countries where regulatory constraints are more lax than in France.

\section{The major retailers}

Although today's consumers drink less wine than earlier generations, they require ever-greater quality, and at prices below Bordeaux's customary levels. The large retail chains' need to push prices lower does not mesh well with consistent quality. This paradox has had a very strong knock-on effect upstream and creates many problems for price negotiations with wine merchants or winemakers. Not only have stringent specifications tightened constraints on the production side but storage and delivery obligations are also being forced upon the retail's sector co-contractors.
The food sector has suffered several major crises pertaining to consumer safety and environmental issues. The large retail chains have been seeking to reassure their customers by increasing product traceability. These new constraints require special monitoring and standards implementation systems, raising acquisition costs that cannot be generalised throughout this structurally fragmented sector.

In the Bordeaux region, $95 \%$ of all Grands Crus top quality wines are sold by wine merchants; $50 \%$ of the wines sold in the larger retail outlets are branded wines; and 31\% of still wines are store brands. This makes it difficult for chains to position themselves in such a way as to further their credibility in the top-of-the-range.

\section{Logistics service providers}

Logistics service providers specialising in the wine business are able to run any and all outsourced logistics activities. They can store wine under controlled temperature conditions; prepare direct customer orders; manage supply, packaging and product wrapping operations for promotional operations or for export; and even take care of bottling and labelling.
Outsourcing these services enables a smooth transition in terms of workforce and workspace utilisation. Winemakers can reduce their outgoings and avoid sunk cost risks. They do not have to invest in machinery anymore and are protected against depreciation or maintenance problems.

In recent times. all of these risks and investments have been assumed by logistics service providers, actors who have to be able to manage physical operations in a correct manner and offer both a quality service as well as an information system that will allow them to interface with their partners - and that will enable their partners to interface amongst themselves.

\section{Overall analysis for the whole of the wine sector}

The tables show the average performances of those wine sector companies that were audited as part of the present study (in comparison with WCL companies' average performance) for the 4 main WCL referential analytical axes (Positioning, Integration, Agility and Performance Measurement) and for each of their sub-axes.

\section{W ine Sector O verall analysis}

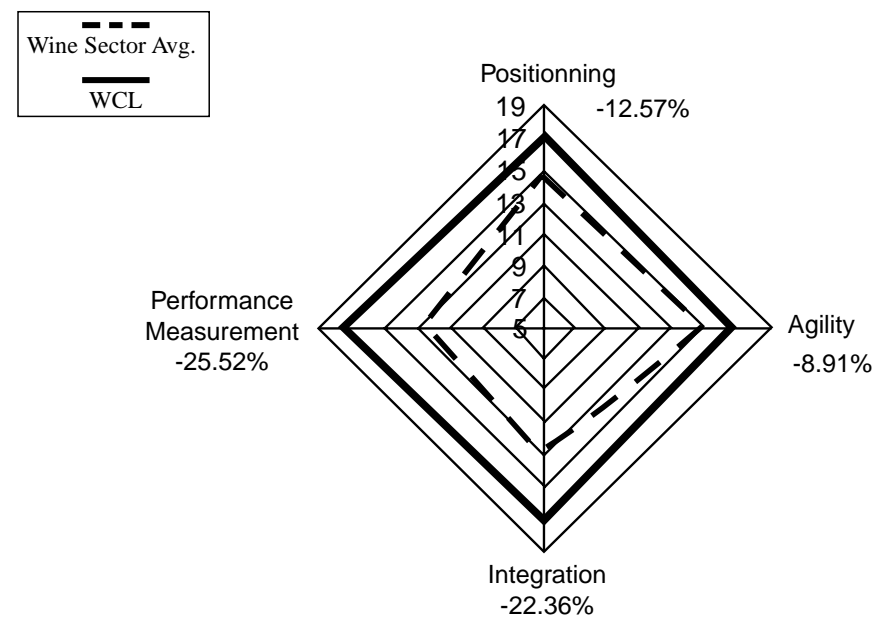




\section{Agility}
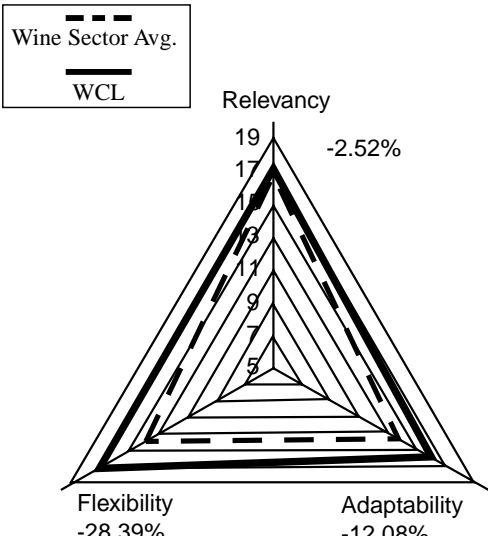

Performance measurement

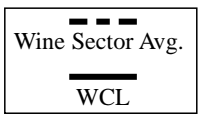

Functional

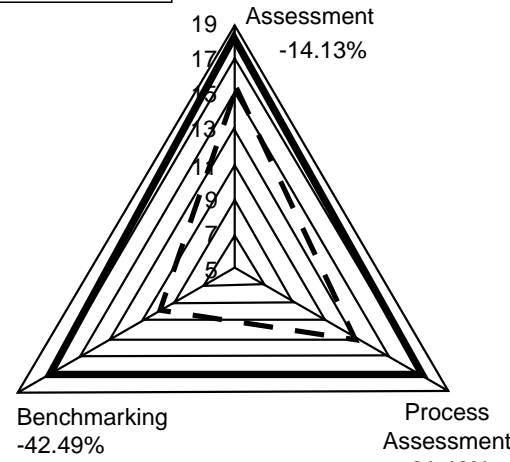

\section{Integration}

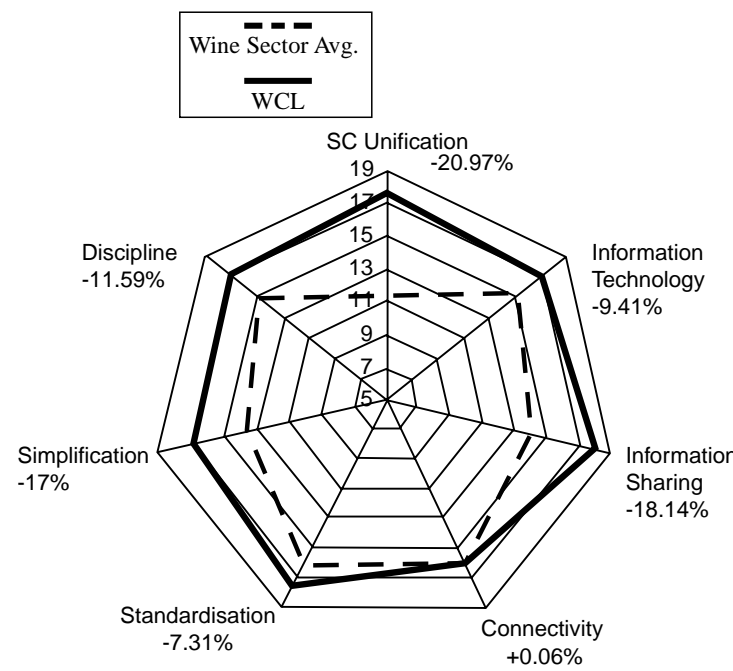

Agility (-8.9\% / WCL)

The Agility axis is the one where the wine sector companies perform best, achieving a score of $-8.91 \%$ versus WCL.

This is because in their efforts to counter the attack from New World wines, the French wine players have been reacting to current circumstances and asking questions about what the market really wants.

This means that they have been listening closely to customers' requirements (Relevancy: $-2.52 \%$ / $W C L$ ) and providing very appropriate responses, be it in terms of Adaptability (-12.08\% / WCL) or Flexibility (-28.39\% / WCL).

\section{Performance measurement (-25.52\% / WCL)}

Performance Measurement is the aspect where companies in the Bordeaux wine supply chain have the most catching up to do: - $25.52 \%$ / WCL. This observation does not provide the full picture, however. Wine sector actors have been very careful to measure their internal logistics performance in terms of customer service, productivity and quality. This is because they have been implementing a greater number of more efficient Performance Measurement systems than they were just a few years ago. Hence their relatively good performance in Functional Assessment (-14.13\% / WCL).

On the other hand, they undertake fewer external measurements of logistics performance (Process Assessment: $-21.46 \%$ / WCL) and rarely apply Benchmarking. This can be explained by the fact that wine sector companies are generally small in size and do not have the human resources or time to develop said activities. Furthermore, the wine sector is a highly competitive environment where actors are very reluctant about exchanging the kinds of information they can get from strategy comparisons.

\section{Integration (-22.36\% / WCL)}

Integration is one area where wine sector companies perform relatively poorly in general. However, since this axis is comprised of 7 sub-axes, performances should be analysed separately.

Good scores in Information Technology $(-9.41 \%$ / WCL), Connectivity $(+0.06 \% / \mathrm{WCL})$ and Standardisation (-7.31\% / WCL) show that wine sector companies have invested in resources (notably IT-related) that will enable them to perform well whenever information is to be exchanged by means of efficient joint procedures. Many of the companies audited in the present study are ISO 9001 certified, in large part because they have done so well in this respect.

Note also a very good performance for the Discipline criterion (-11.59\% / WCL). This shows how committed wine branch actors are.

On the other hand, performance lags along sub-axes such as Simplification $(-17 \%$ / WCL), Information Sharing (-18.14\% / WCL) and SC Unification (-20.97\% / WCL), which refers to cooperation-based relations between logistics partners. This can certainly be explained by the diffuse nature of the Bordeaux wine supply chain (meaning that this is a chain that features many links and actors) and fragmented. A plethora of parties get involved at every stage, notably at the winemaker or wine merchant level. This complex network does not facilitate the integration of its constituent companies. 


\section{Positioning}

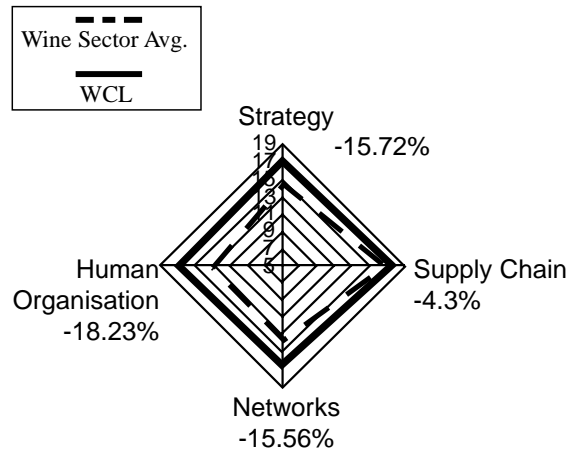

\section{Winemakers}

\section{O verall analysis}

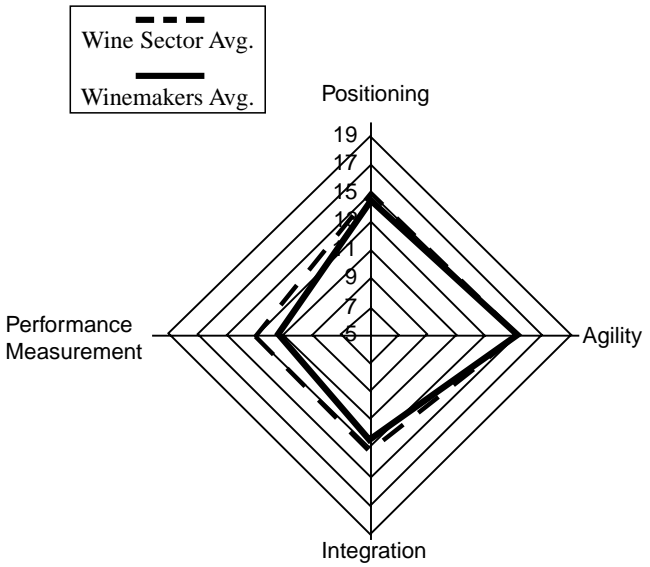

\section{Positioning}

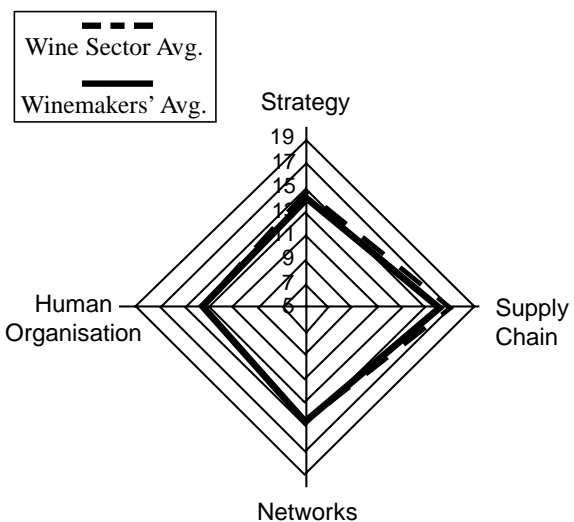

\section{Positioning (-12.57\% / WCL)}

Wine sector companies maintain a relatively good Positioning on average : $-12.52 \% / \mathrm{WCL}$.

The excellent Supply Chain mark (- $4.3 \%$ / WCL) attests to companies' willingness to establish collaborative arrangements with their partners. These strategic intentions are seen as a way of improving synchronisation between logistics resources.

Despite actors' clear awareness of this imperative, the low marks for Strategy (-15.72\% / WCL), Human Organisation (-18.23\%/WCL) and Networks (-15.56\% / WCL) show that wine sector companies still find it difficult to devise a specific facility location strategy, to ascertain which service levels their customers expect, to manage stock replenishment, etc. This can be explained by the current climate, marked by the wine branch's general doubts regarding the best way of countering competition from the New World.

\section{Winemakers}

\section{Overall analysis}

Winemakers' overall outcomes, whether at an individual level or when combined into wine co-ops, denote strong Agility capabilities. These are companies that can control product supply and keep close tabs on market developments. They are therefore in a position to take those strategic decisions that will allow them to service the entire market. With respect to Supply Chain and Integration, winemakers rarely have a visibility of the downstream side and rarely exert any control over it.

In general, their results are in line with the chain's average performances.

\section{Positioning}

Winemakers' results in terms of Positioning (the strategic and structural orientations they choose when trying to optimise their logistical operations) are almost exactly the same as the average results for the whole of the supply chain. This stems from the fact that most of the chain's value-added is concentrated in its wine-growing and vinification stages.

The chain's downstream links will therefore plan their logistics, notably their transportation needs, in such a way as to accommodate the varying constraints that winemakers force upon them. For example, most domains or wine co-ops sell their goods at a "factory gate" price or else simply re-invoice any transportation costs that they have to pay first.

Where there is a partnership with a wine merchant or a retailer the downstream partner will be the one responsible for getting the product picked up and for transferring ownership.

To minimise the transportation cost's impact on the consumer price it is preferable that the actor who does the biggest volumes be the one in charge of transportation. In other words, the distributor, wine merchant or major retail chain, working either through a service provider or else directly, should be the one to try to optimise pick-ups and final delivery. This is because of these actors' level of logistics maturity their transportation management competencies are greater than winemakers'. 


\section{Integration}

Winemakers are generally less integrated with the supply chain than downstream actors are. This is true even though in Supply Chain Unification terms winemakers perform better than the other actors, notably due to their need to create downstream partnerships to

\section{Integration}

$$
\begin{array}{|l|}
\hline \text { Wine Sector Avg. } \\
\text { Winemakers' Avg. } \\
\hline
\end{array}
$$

SC Unification

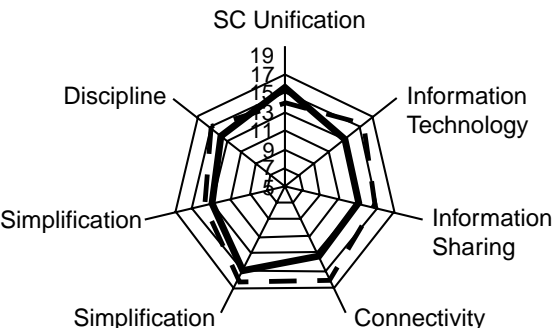

\section{Agility}

$$
\begin{aligned}
& \text { Wine Sector Avg. } \\
& \text { Winemakers' Avg. }
\end{aligned}
$$

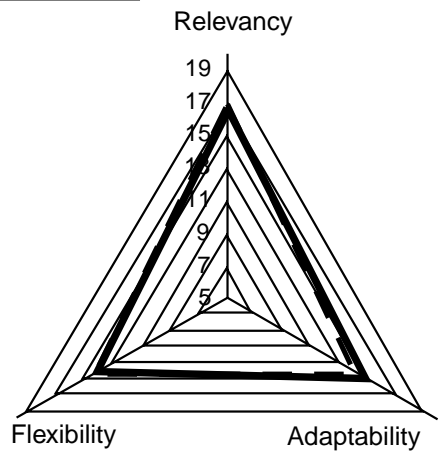

ensure that they will be able to sell their products in optimal conditions.

Few operational or strategic information exchange or compilation systems have been implemented. This can be explained by the fact that such actions entail major outlays - and by the view that there can be little return on investments of this sort.

There are a number of Internet and satellite network-based IT and technological resources enabling a real-time analysis and monitoring of grape-growing and vinification activities. These new technologies would make it easier for wine merchants or distributors to check that their specifications are being complied with. They would also enhance winemakers' control over product quality. However, for a number of reasons these sorts of technology are still not being used very often. It is extremely rare that winemakers possess the level of IT competency their installation requires. Moreover, such technologies are still at a basically experimental stage, due to winemakers' relatively weak commitment to highly technological solutions. People perceive the cost represented by an investment of this sort as an added risk at a time when the market is going through a lot of changes.

EDI implementation is somewhat more widespread, but is essentially only of concern to those winemakers who entertain direct relations with the major retailers. In actual fact, driven by their base of large retail customers, big volume wine merchants and wine co-ops have already implemented a number of IT-based data transfer systems. Major retailers are ready to deal with winemakers who have not set up EDI, but in this case information exchanges will be EDI-based as far as the wine merchant before involving other vehicles (fax, telephone) for communications with the winemaker. For smaller quantities, faxes are sometimes sent directly to the winemaker by the distributor.

Regulatory constraints are also a major impediment to process Simplification. So is market volatility, which is a side-effect of the new competitive situation. Fluctuating grape-growing conditions can also hamper the implementation of standardised procedures.

\section{Agility}

As is the case with Positioning, the results obtained here basically match the average for the whole of the wine chain. Performance Measurements have highlighted winemakers' ability to adapt to market developments.

This Adaptability performance is due to winemakers' building of stocks of finished products, something that helps them to rapidly service a market marked by its highly volatile consumption patterns

Winemakers perform well in Flexibility terms, achieving significant variability by deferring inputs into a supply chain that is generally characterised by the intensity of its flows. After all, even if production forecasts by definition incorporate the concept of intensive flows, purchases are often made at the very last minute and product wrapping will only take place once the sale is certain.

These observations pertain to the largest individual actors but also to the smaller domains, which are indirectly involved via wine co-ops. 


\section{Performance measurement}

Performance measurement

\begin{tabular}{|l|} 
Wine Sector Avg. \\
Winemakers' Avg.
\end{tabular}

Functional Assessment

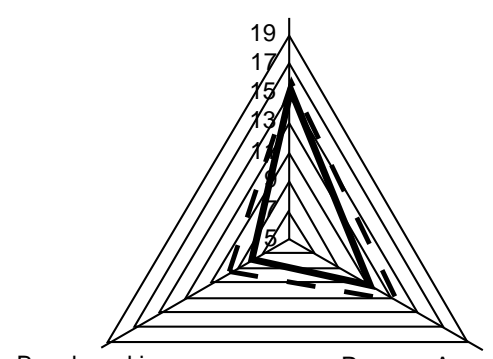

Process Assessment

Benchmarking

Wine merchants

O verall analysis

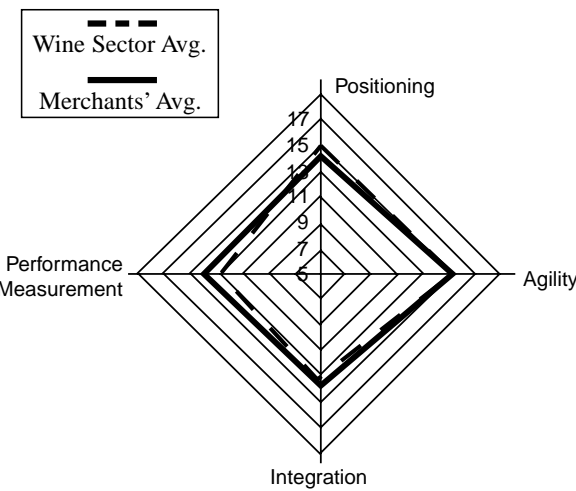

A gility

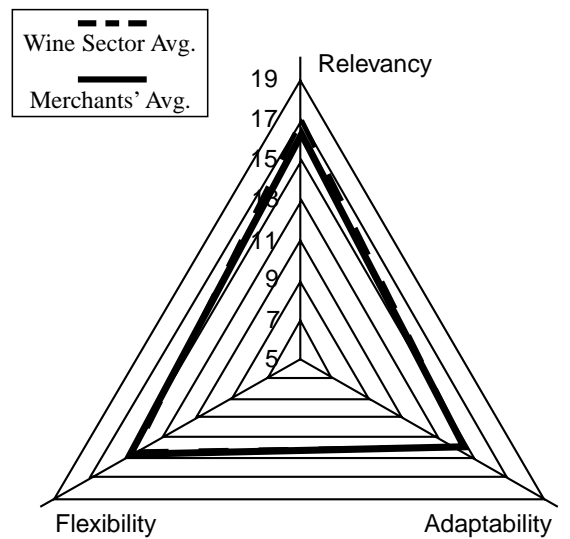

This is the area where winemakers perform the poorest. They control the lion's share of the value-added that is generated in this sector and are therefore not very concerned with the way in which the supply chain performs, preferring to focus more on internal Performance Measurement

Companies in this sector make little use of Benchmarking and do not like divulging their internal performances.

The deficiencies that have been observed are a reflection of winemakers' lack of logistics maturity. They often do not have a logistics culture and they possess few competencies in this field. There is no attempt to anticipate logistics problems, which are frequently contended with only when an emergency arises. Where logistics are externalised to service providers, this often comprises an attempt to externalise a problem and not to free up assets that can weigh upon a balance sheet.

\section{Wine Merchants}

\section{Overall analysis}

The Tables below show average performance for the wine merchants who were audited in the present study, in comparison with the average performances of all wine sector companies under study.

\section{Agility}

The Agility axis is the one where wine sector companies perform the best.

The same applies to the wine merchant link in this chain, which performs similarly to the overall sectorial average (with a gap of less than 1 point for each of the Agility sub-axes)
Wine merchants' excellent Relevancy performance attests to their proactive attitude towards a market going through a process of change.

Regarding Adaptability and Flexibility, the wine merchants' performance matches the sectorial average. The merchants interviewed here did however manifest varying degrees of maturity in this respect. Where there is a risk that they could run out of stock, they know how to modify their organisation in such a way as to enhance customer satisfaction (notably in time-tomarket terms) by responding quickly to emergency situations. One example is a company that ships all of its flow via a logistics service provider but which discards this standard circuit in case of an emergency and replaces it with direct (and therefore much quicker) deliveries to the customer.

In addition, standardisation (particularly of packaging and labelling) also makes it possible to defer product differentiation. Companies can fill a specific order within a very short period of time both because they practice deferred differentiation and also because they have set up systems to accommodate intensive flows, something that has become becoming increasingly crucial. 
Performance measurement

Wine Sector Avg.
Merchants' Avg.

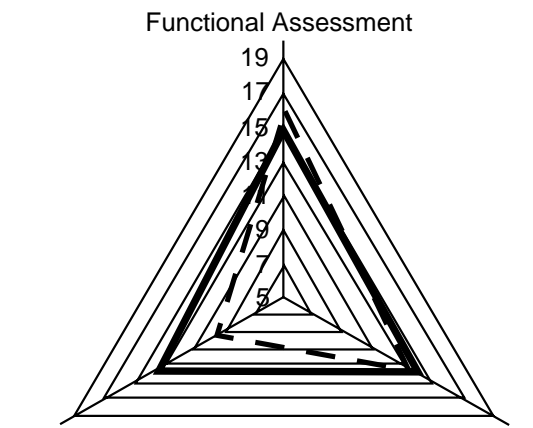

Benchmarking Process Assessment

\section{Integration}
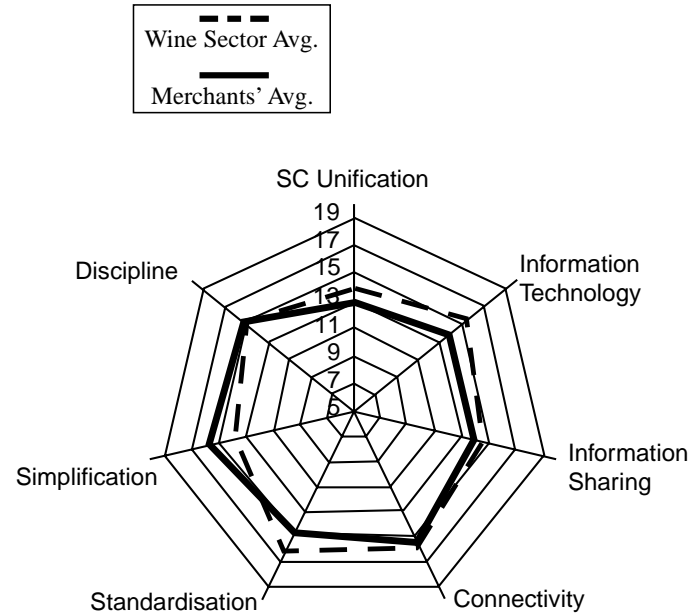

\section{Performance measurement}

Performance measurement is where the companies operating in the Bordeaux wine supply chain perform the worst.

Wine merchants' performance is 1 point above the branch average, however.

The Choice of Relevant Indicators sub-axis is the one with the best level of performance. After all, wine merchants measure service rates in terms of order availability, the number of customer complaints and the gap between actual outcomes and forecasts (i.e., the quality of commercial forecasting). Where a Quality function exists, performance indicators improve constantly due to the curative, corrective and preventive actions that companies undertake to try to ascertain and implement "best practices".

SC Process Evaluation scores slightly lower because there are fewer ways to measure logistics partners' performance. Wine merchants' current priority is to optimise their company's own performance. In addition, customer satisfaction surveys are either inexistent or else not very formalised.

Regarding SC Unification, very few operations are integrated with one's partners, notably due to the irregular nature of the relationships in this chain. Hence the wine merchants' poor score in this area.

IT management systems are used for to plan and manage logistical operations, purchasing, stocks and sales. However, these systems are relatively old and not very integrated. Moreover, one of their deficiencies is that they lack the future planning software that would help them to better pilot their purchasing activities as well as their production inputs. Lastly, EDI transmissions have not generalised, meaning that they are still only being used for the most important customer relationships.

Some information is shared with partners, notably for marketing purposes. This involves product design in particular (i.e., store brand labels are co-designed with the major retailers). However such information sharing is not very computerised.

Quality functions are being used to set up work procedures that clearly identify each operation, thus guaranteeing an efficient level of Standardisation. Furthermore, a Simplification policy has become a necessity, what with the increased number of references that have to be managed.

On the Benchmarking sub-axis, wine merchants perform score 3.5 points higher than the sectorial average. This is because they are aware of their partners' performances, which they can compare with their own.

\section{Integration}

Integration is one area where wine companies perform poorly in general. Wine merchants do slightly better, scoring 0.5 points higher.
Lastly, and as is the case for the entire Bordeaux wine branch, note performance, translating actors' strong commitment to company life. the very good Discipline 


\section{Positioning}

On average, wine sector companies' Positioning is relatively good, more or less matching wine merchants' score in this area. There are a number of sub-axis divergences between the two, however.

\section{Positioning}
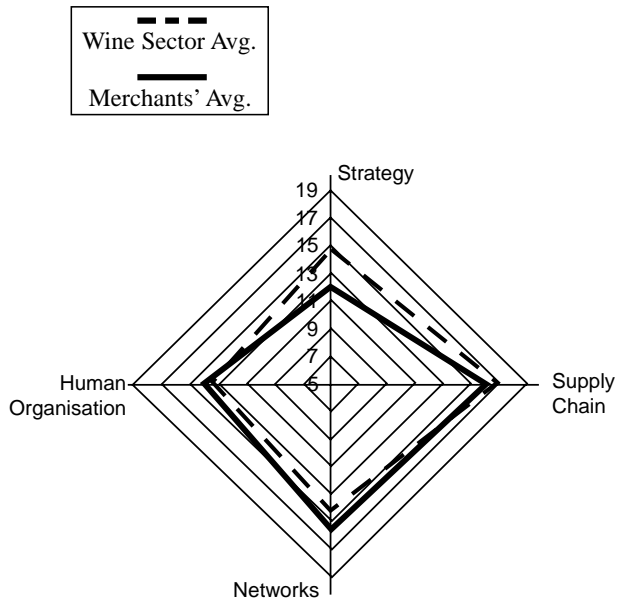

3PL/Transporters

O verall analysis

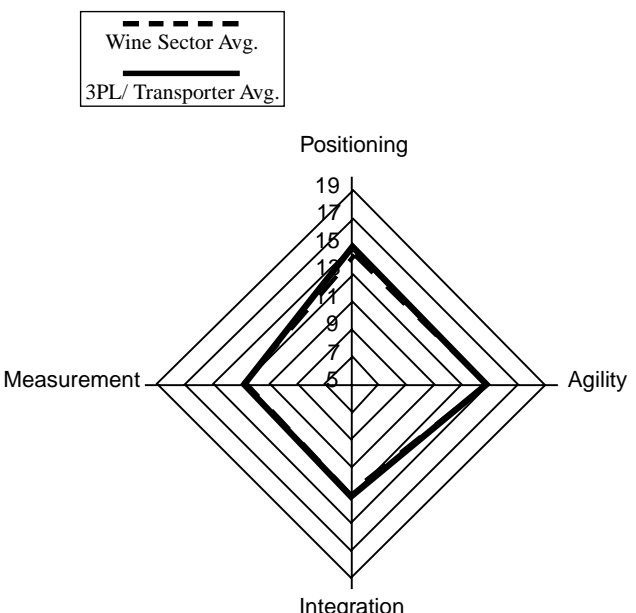

Regarding Strategy, wine merchants score far below the sectorial average ( 2.5 points). On one hand, they work under emergency conditions, lack long-term visibility and do not try to predict future demand patterns. Furthermore, their various divisions pursue contradictory objectives without any consideration being given to the specific constraints that each has to cope with. Optimisation is achieved at a functional rather than at an overall company level.

Wine merchants' excellent Supply Chain score attests to their willingness to establish collaborative arrangements with their partners, and also to commit to shared goals. Their score along the Infrastructure-Networks sub-axis is 1.5 points higher than the sectorial average. This reflects their commitment (unlike other actors) to a complete reorganisation of their warehouse management function, and of their raw material and finished product management systems.

In terms of Human Organisation, wine merchants score about the same level as the sector average. Company operations are facilitated by their relatively flat hierarchy, outstanding inter-personal communications and polyvalent staff members.

Wine merchants would do well to think about developing EDI with a greater number of customers. This is because the quicker they recover information the better they can predict customer needs. Moreover, applying EDI to their downstream relations will help them to set up a leaner system for sourcing dry materials. This approach would allow for a significant reduction in raw material stocks, thus freeing up frozen assets and improving companies' cash positions.
Furthermore, standard operational information should be shared systematically via a computerised information system. This would accelerate responses to customer demands and optimise the planning function, inasmuch as customer needs would be received in real-time.

The overall advantage to be gained would be greater agility to fluctuations in market demand.

\section{Logistics service providers/Transporters}

\section{Overall analysis}

Transporters are service providers working on behalf of winemakers and wine merchants to ship winemakers' goods to end users, whether or not they go through logistics service providers.

Logistics service providers offer subcontracting services on behalf of winemakers and wine merchants, including bottling, warehousing, labelling, product wrapping, advice, etc. We have combined these two types of actors into a single link in the logistics wine chain due to the similarity of the services they offer.

In general, since logistics constitute service providers' core business, they score well in Supply Chain performance terms when compared the whole of the wine chain.

In particular, note that their average Positioning and Integration scores are higher than the branch average. For Agility and Performance Measurement, they average about the same as the branch as a whole. 


\section{Positioning}

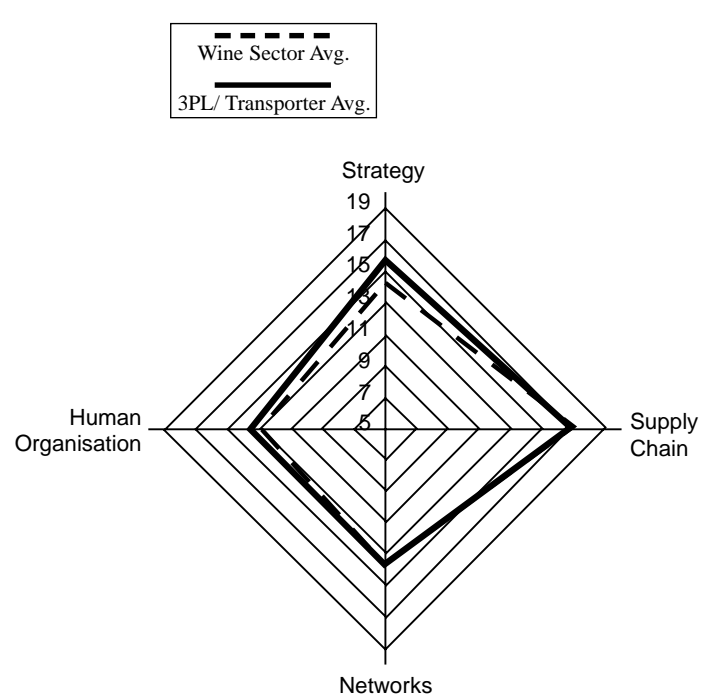

Integration

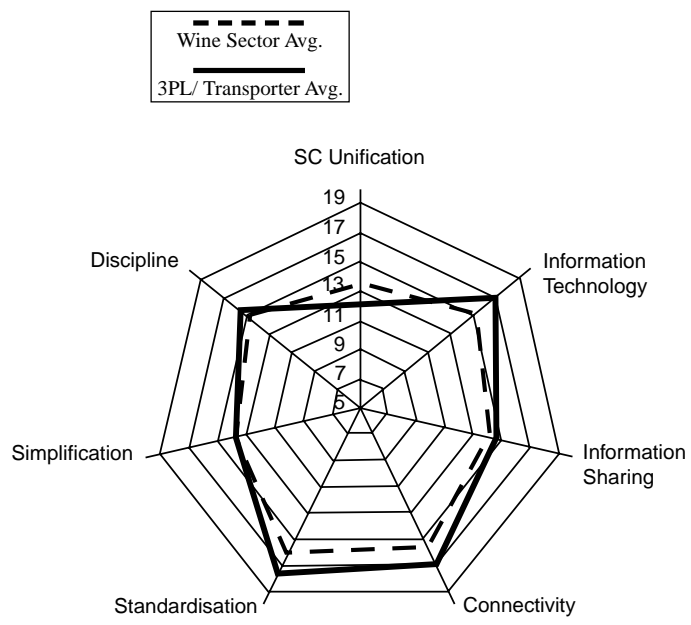

\section{Agility}

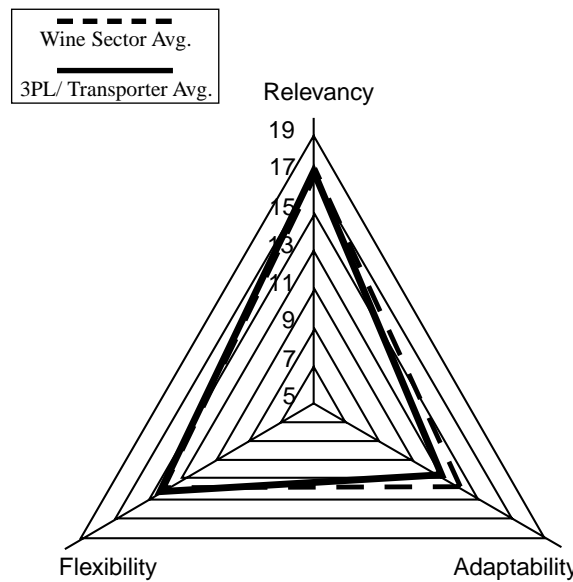

\section{Positioning}

Logistics service providers perform remarkably well here, obtaining the highest average of any of the links in the wine logistics chain.

To organise their own work more efficiently, service providers use standardised procedures that categorise customers by their logistics requirements. All processes are structured with a view towards maximising the logistics performance (the goal being a "faultless" performance) and the service rate. Exceptional demands are dealt with via new processes that are subsequently generalised to other customers.

As regards inventory management service providers depend on their customers' decisions. Service providers have no influence on the quantities they will be storing or on the retail modes they will be using (which correspond to constraints that their clients have forced upon them). This means that stock turnover is not a significant performance indicator.

\section{Integration}

Integration is also one of the logistics service providers' stronger points.

Service providers set up pre-established procedures they will follow when responding to customers' varying requirements.

At the Supply Chain Unification level service providers compile extremely precise specifications to define each of their partners' role. Certain tasks (i.e., labels and product wrapping materials sourced from outside suppliers) are integrated with some of their partners.

Service providers invest much more than the chain's other actors in information technology, like EDI or the Internet. These technological resources mean they can exchange standardised real-time information with their partners on changes in merchandise flows, and therefore react in case a problem arises Information is also shared with some of their clients.

Where means of communication have been installed on clients' premises, this has often occurred under the aegis of an externalisation drive it is at such times that customers become aware of the importance of being able to control information. Service providers score better on Integration than wine merchants or winemakers do, offering their customers a more integrated service.

\section{Agility}

Service providers offer tailor-made solutions that have been adapted both to the needs of the particular business in question and also to ensure geographic coverage. They pre-define the procedures and solutions that will allow them to cope with their customers' ad hoc requirements, thus to fulfil their obligations with the same speed as if a standard operation were involved.

Because of the density of actors found in the wine chain, service providers have to make considerable efforts to maximise their Agility. After all, this is a factor of competitiveness. Nevertheless, their average score in this respect is slightly below the branch average, due to the significant gap between their average Adaptability performance and that of the sector as a whole.

The lag in Adaptability is due to the constraint that service providers face of having to manage customer stocks which they do not control. This is because service providers are not autonomous - they must obey clients' instructions regarding inventory management. 
Performance M easurement

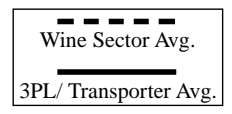

Functional Assessment

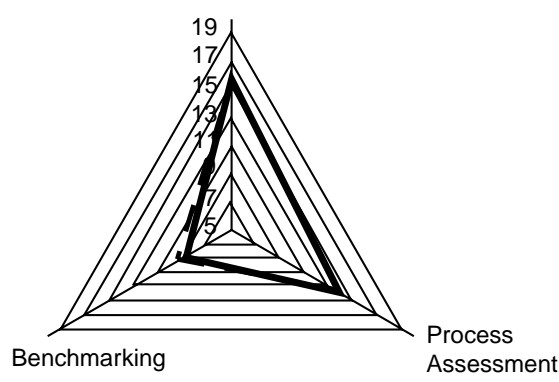

\section{Retail}

O verall analysis

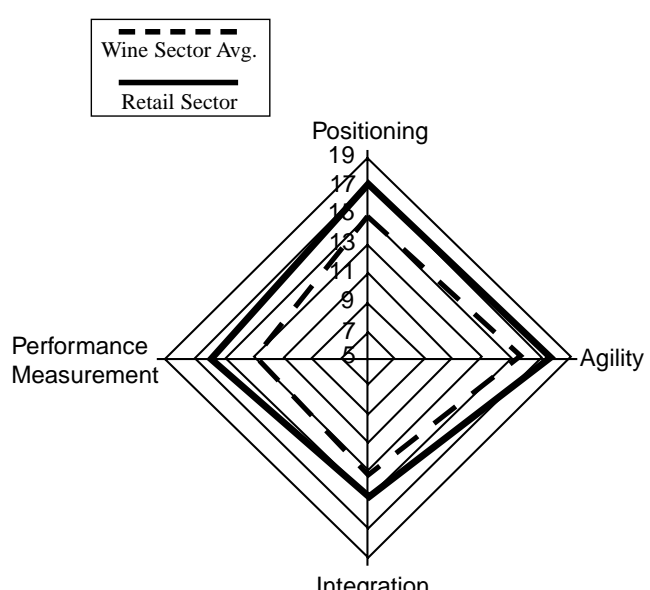

Positioning

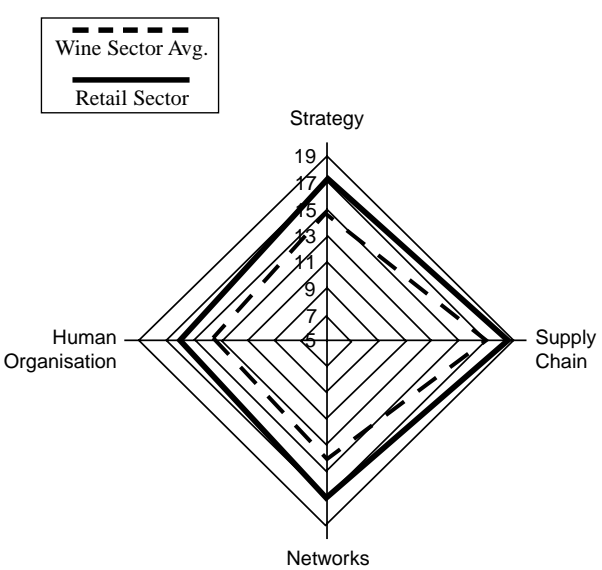

\section{Performance Measurement}

Logistics service providers pay a great deal of attention to customers' reactions to the service they provide. Performance measurement indicators are very releant in this respect. Depending on the financial and humans resources at their disposal, certain service providers organise customer satisfaction surveys. Others compile information in a more informal manner.

External performance measurement can be improved even if service providers score above the branch average in this respect. Wine sector actors traditionally play their cards close to their chest companies prefer to act discreetly and are reluctant to communicate information. Even though logistics service providers in other sectors frequently engage in Benchmarking practices, this is quite a rare phenomenon in the wine sector, despite the wishes of certain service providers.

\section{Retail}

\section{Overall analysis}

The retail sector's overall results are generally high, in comparison with the wine chain as a whole.

This seems to be the link in the wine chain that has the greatest logistics maturity, something that can be explained by the considerable volumes of wine passing through the large retail chains (Intermarket for example distributes upwards of 250 million bottles a year). Another explanation is that competition between retail chains has become so intense that the various actors in this area have had to optimise their logistics function to lower their prices.

Performance Measurement is the aspect where this link performs best when compared with the rest of its chain. To manage the multitude of references being distributed across national and international networks, actors need to have implemented a very rigorous system of monitoring and analysis.

Positioning is the area where the retail sector score the highest. This is because of the fact that retail chains operate in an oligopolistic market. More specifically, $70 \%$ of all physical flows in the wine chain are centralised at this level. What we can deduce from this is that the strategic orientations and structural resources that have been implemented to develop wine retail activities have been successful.

\section{Positioning}

Theretail sector's Positioning performances are much higher than the rest of the chain (averaging $+14 \%)$, but its overall performance curve is similar.

This can be explained by the fact that supply chain resource synchronisation is such an effective action. Major retailers have been signing an increasing number of long-term partnership agreements with other actors in the wine chain (wine merchants, winemakers and service providers) and integrating them into their logistical operations (continuous stock replenishment, total flow traceability, etc.). The specifications governing such partnerships are updated frequently. In addition, some chains own their own truck fleet, as well as subsidiaries in the bottling and product wrapping businesses.

Infrastructure and network investments have made the goods' flow as lean as possible by minimising stocks and by shortening order processing and delivery cycles between suppliers and purchasing combines and between purchasing combines and points-of-sale.

Retailers generally opt for internal logistics strategies that are diversified and can be adapted to a variety of needs. Point-of-sale deliveries are made by rail and by road, at optimised frequencies and quantities. These performances have enabled an average reduction in logistics costs of $4-5 \%$ of the goods' post-tax sales price. 


\section{Integration}

The big retailers perform best in terms of Information Technology and Sharing, and also regarding Connectivity.

Indeed, the large retail groups were the original drivers behind the implementation of EDI in the food sector, and more specifically in the wine branch. Major retailers work via EDI with most of their suppliers and partners, although they are willing to use more traditional methods to communicate with small suppliers. Large retailers in the Gironde Department surrounding Bordeaux usually go through wine merchants when trying to source from smaller winemakers. Orders are communicated by EDI to the wine merchants, who then communicate with the winemakers by fax or telephone. When a retail chain wants to add a particular winemaker to its list of references, it will delegate sourcing and storage operations to a wine merchant.

This preserves traceability throughout the chain without forcing any specific communications standard upon winemakers. Internally, retailers' proximity to the end user gives them information and helps them to come up with accurate consumption and demand forecasts that they can update daily.

Partnerial cooperation is formalised by specifications that will be updated once a year. Retail chains integrate a great many operations with their partners but risks are not yet shared in an optimal manner, since most are still being incurred by the suppliers. This imbalance has tended to even out thanks to France's New Economic Regulations, which attempt to reduce de-referencing risks for those suppliers who are very dependent on the major retailers.

The big retail chains also find it hard to get their staff on board for their product handling operations.
Wage incentive schemes (mostly performance-linked bonuses) are not considered very efficient, often leading to high staff turnover in the purchasing combines or warehouses.

\section{Agility}

Regarding Agility, the retail sector performs worst in matters relating to the Relevancy function - whilst still scoring better here than the chain does as a whole (since the retail link is the one closest to the product's end users). Retail chains do after all possess a wealth of information on consumption behaviour. This data is frequently used during the marketing of store brand products.

Relevancy and sales promotion actions have been proliferating. Note the increasing success of wine trade fairs (organised by all major retail chains nowadays) and of customer loyalty cards, which make it possible to centralise even more information on wine consumption.

The big retailers' Adaptability score attests to a large outlet's ability to reference any and all types of products, rather than to merely handle specific demands.

On the other hand, certain retail chains give their points-of-sale the freedom to source directly from regional winemakers, so as to be able to offer products that are specific to local consumption behaviour. For example, more Bordeaux wine references can be found in the big stores in the Gironde Department than anywhere else in France.

The high Flexibility score mainly reflects the retail chains' ability to adopt a lean workflow when trading with suppliers who sell whatever products they currently have in stock. Retailers can for example make sure that if demand is ever much higher than forecasts, their stores will take longer to run out of stock than the time required to replenish them. It therefore occurs quite infrequently that a store's wine section runs out of stock. This happens with less $1 \%$ of total volumes in this sector. 


\section{Performance M easurement}

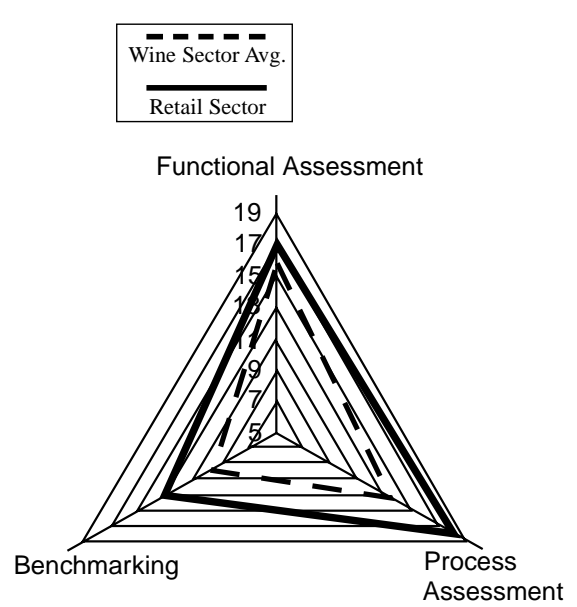

\section{Performance measurement}

Major retailers are generally very aware of their competitors' performances and practices. They may not always undertake any real Benchmarking but they do gather information via their many service providers or shared suppliers.

On the other hand they rarely compare themselves with companies operating in other sectors of activity.

Supply Chain Processes are monitored particularly closely. Before referencing a new wine supplier, a quality audit will be carried out on-site. This is redone every year and culminates in a ranking. A supplier's position therein will determine its referencing for the following year.

Furthermore, activity-based cost breakdowns constitute a technique with which these actors are perfectly familiar. Suppliers are often chosen based on their total cost.

Branded wines are wines that have been blended from the output of several winemakers and matured in cellars.

Model 1

Branded wines

Examples of branded wines:

- Kressman Monopole

- Blaissac

- Baron de Lestac

- Malesan.

Winemakers or wine co-ops grow grapes and are responsible for vinification and blending (and sometimes for bottling). Otherwise bottling, labelling and packaging operations are carried out by Logistics service providers.

In most wine merchants' opinion, a company's main strength is its brand name. Ginestet's Managing Director says for example, "Bordeaux's brand name is its ace in the hole against New World wines".

With branded wines it is possible to produce large volumes of wine of consistent quality.

This model is characterised by the strong value-added that derives from communications. This means that the wine merchant is the strong link in this particular supply chain.

Wine merchants transmit operational information (sales forecasts, blending specifications, bottling, labelling, packaging) to service providers and winemakers. Wine merchants

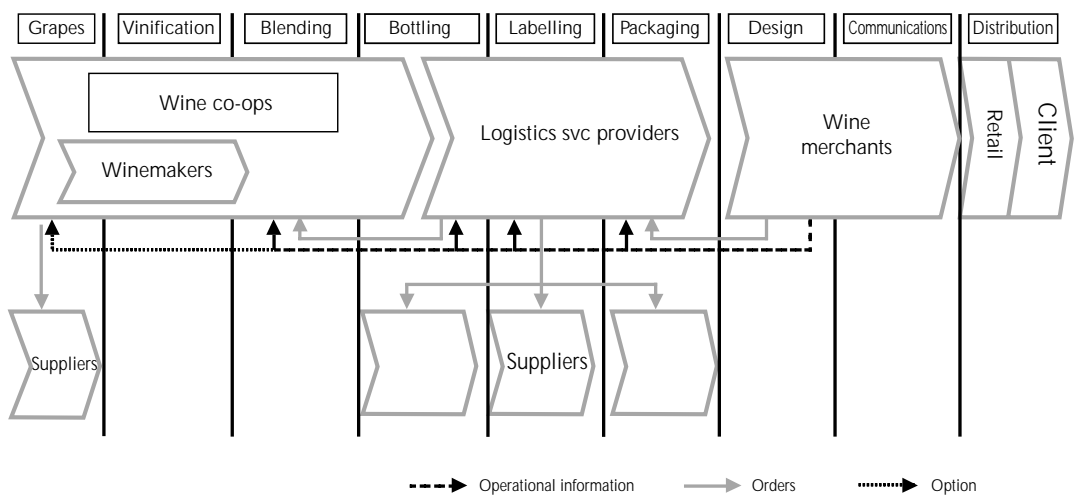

sometimes determine grape-growing specifications in the branded wine supply chain, although not always. Every time a service provider receives an order from a distributor it will either send a further order on to the supplier or winemaker or else draw from its own stocks.

Wine merchants work closely with consumers and are therefore very aware of market trends. As a result, they are the ones to decide which wines to market. This takes power away from winemakers and leads to lesser product diversity. Winemakers no longer control the composition of their wines.

In time, wine merchants will seek to take over production activities and drive this function from the downstream side. This piloting will be mainly achieved through partnerships and alliances. To devise a system in which vineyards are customer-driven and to carve out a crucial role for themselves, wine co-ops will have to merge so that they can develop the technical and human resources that are required to fulfil a partner's role. If vineyards are to be efficiently managed from the downstream side, wine co-ops will have to be able to determine their own grape specifications and pricing schedules.

Information on orders circulates from one link in the chain to the next, starting downstream and moving backwards. One criterion of success is the ability to work within a highly integrated chain, one that uses a standardised type of information. 
Model 2 :

Store brands

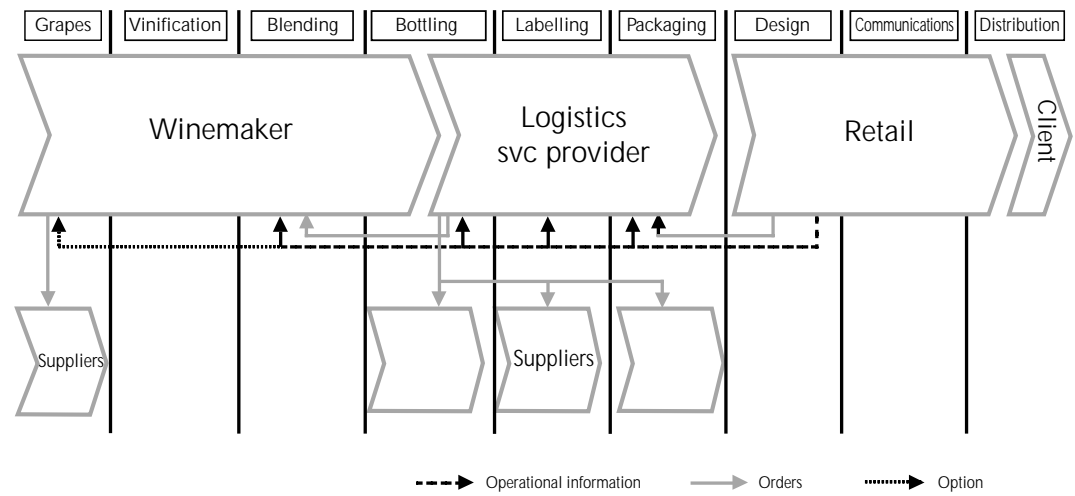

In this supply chain, winemakers are in charge of grape-growing, vinification and blending. Bottling, labelling and packaging operations are carried out by the logistics service providers. This is a configuration where the wine merchant level has been eliminated. Major retailers play a role in product design and communications. They source directly from winemakers and become the chain's key link, replacing wine merchants.

The major retailers are the ones steering the information flows, much as wine merchants do in the branded wine supply chain (c.f., model 1 ). In the store brand supply chain however there is a higher degree of commercial integration, due to the retail sector's greater ability to exchange information in real-time.

All flows are piloted on the basis of forecasts that are updated daily in such a way as to reflect actual consumption. This and the lean management of flows are what explain the chain's flexibility.

The risk with this particular supply chain structure is that it is piloted by actors who are not wine sector specialists. This reinforces major retailers' power over winemakers and causes an imbalance in their relationship.

Major retailers are very involved in this kind of strategy. Store brands have risen sharply over the past decade and account for about $30 \%$ of all sales of wine in major retail outlets. Products of this nature can supply structure, is no easy task. It remains to be seen whether collective campaigns have an efficient impact on consumers' purchasing acts.

In the export markets, promotion is undertaken by Trade Association task forces and by ONIVINS.

There are three types of collective communications:

- communications highlighting all French wines

- specific communications focusing on the country's main winegrowing regions

be expected to undergo a number of changes in the years to come.

Today store brand wines amount to something like 100 millions bottles of red and white Bordeaux wines per annum.

This schema characterises the Grands Crus logistics chain by depicting the traditional breakdown of value-added in the Bordeaux wine region. In this chain it is difficult for the winemaker to get demand-related information, and value-added operations are distributed unevenly.

In terms of product promotion, (French) nationwide communications are organised by Trade Associations and funded by membership fees. Collective communications account for $48 \%$ of advertising expenditures. However, promoting this category of wine, with its highly dispersed

- communications lying somewhere between brand advertising and generic publicity

Looking to the future, the wine merchant level, which accounts for 95\% of Grand Cru flows

throughout this chain, runs the risk of losing market share to the major retailers, who have been increasingly positioning themselves in the market's top-of-the-range segment.

Lean workflows predominate in this model, one in which logistics performance is taken very seriously. Winemakers are the key actors in this logistics chain.

The fourth schema is characterised by winemaker's involvement in all of the chain's value-added activities, albeit with occasional help from logistics service providers.
Model 3

\section{"Grands Crus"}

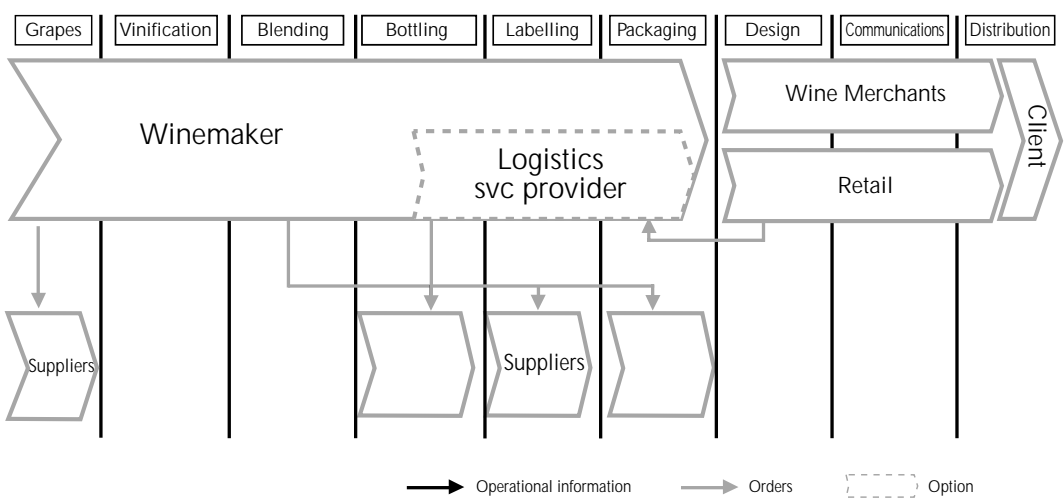




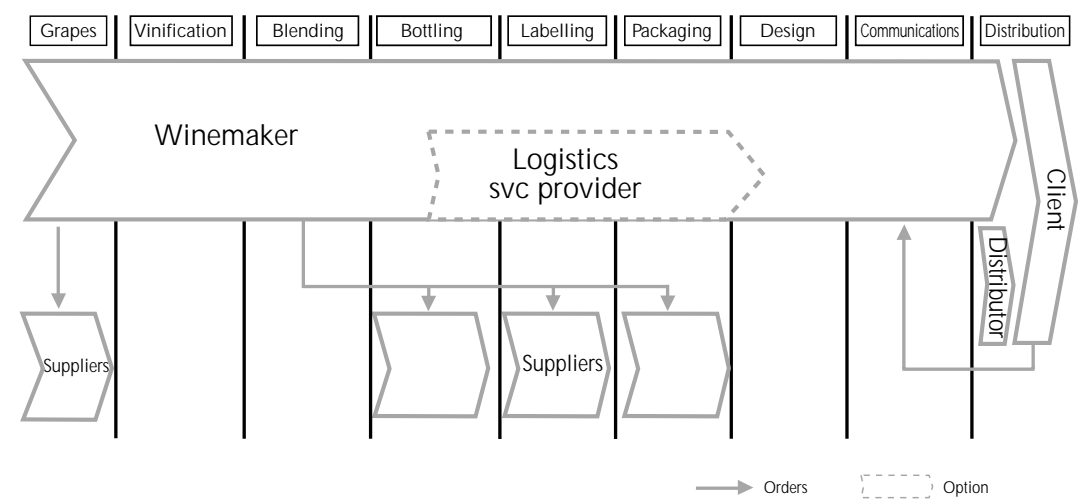

This model enables a great deal of agility to changing market demand inasmuch as winemakers, who are the main actors in this chain, are in close touch with the end user.

The model's drawback is that winemakers must possess a great deal of logistics maturity, given the multitude of activities they undertake. An awareness of logistics is something new to winemakers whose core business is wine production. Furthermore, wine merchants no longer act as logistics partners in this model. This precludes any strong marketing action promoting the wines.

Winemakers focus their efforts on vinifiation, this being their true profession. They increasingly turn to outside service providers for other operations.

In this model, the winemaker is practically the only actor in the logistics chain, and therefore captures all of the value-added.

\section{Conclusion}

Out of the four schemas we have presented at the end of our study, two are clearly destined for further growth. These are the "branded wines" and "store brands" models. The reason is that these wines mesh well with the current changes occurring in the Bordeaux wine branch. On one hand, they offer an efficient response to the attack from New World wines. On the other, major retailers have tended to play an increasingly important role as a link in these chains, to the detriment of wine merchants. The two schemas also fit in with the supply chain's general shift towards a downstream piloting of vineyards. The structure of the supply chain for Grand Cru wines is unlikely to change in the years to come due to the legal constraints to which AOC winemakers are subjected. Logistics service providers will continue to be involved in the same bottling, labelling, packaging, storage and handling operations as the ones being delegated to them currently, mainly for high value products. 